\title{
IDENTIDAD Y ASISTENCIALISMO MUTUAL Y BENEFICIENTE: EL ASOCIACIONISMO ESPAÑOL EN LA EMIGRACIÓN A AMÉRICA
}

\author{
Juan Andrés BLANCO RODRÍGUEZ \\ Universidad de Salamanca
}

Recibido: $01 / 03 / 2011$

Aceptado: 28/06/2011

RESUMEN: El asociacionismo constituido por los emigrantes españoles en América supone uno de los elementos más relevantes de su actuación colectiva. Crearán, desde mediados del siglo XIX, más de 2.000 asociaciones de carácter benéfico, mutual, recreativo, cultural, económico, deportivo o político en las que se integran más de un millón de asociados. Junto a las globalmente españolas existirán otras que agrupan a los procedentes de las distintas regiones y provincias, e incluso (en especial entre la colectividad gallega) a los nacidos en una misma parroquia, ayuntamiento o comarca. Este asociacionismo se desarrollará fundamentalmente en los países que reciben contingentes significativos de la emigración española y tendrá su periodo de esplendor en las tres primeras décadas del siglo XX, siguiendo muchas asociaciones vigentes en la actualidad, si bien su actividad se ha reducido y modificado sensiblemente.

PALABRAS CLAVE:asociacionismo, beneficencia, migración, mutualismo, sociabilidad.

IDENTITY AND MUTUAL ASSISTANCE AND CHARITIES: THE SPANISH ASSOCIATIONS IN THE EMIGRATION TO AMERICA

ABSTRACT: The associationism established by Spanish immigrants in America is one of the most relevant milestones of their behaviour as a group. From the middle of the 19th century on, they create more than 2,000 associations of charity, mutual, leisure, cultural, economic, sport or political character in which more than a million members take part. Apart from the totally Spanish ones, there are others which bring together those people coming from the same regions and provinces or even, especially among the Galician community, those born in the same parish, municipality or region. This associationism develops mainly in countries which receive significant numbers of Spanish immigrants, reaching its peak during the first three decades of the $20^{\text {th }}$ century. Many of those associations still exist, although their activity has declined and changed considerably.

KEY WORDS: Associationism, Charity, Migration, Mutualism.

\section{INTRODUCCIÓN}

Las asociaciones creadas por los emigrantes españoles en América consti- 
tuyen uno de los elementos más relevantes de su actuación colectiva. Por otro lado, buena parte de la recuperación de la visibilidad de estos emigrantes ha sido posible a partir de estas entidades asociativas. Las asociaciones son la memoria institucional de la emigración y la parte más visible de ella (BLANCO, 2008: 9). En ellas se ha reflejado una cierta memoria colectiva de la emigración y dentro de las mismas se han evidenciado las tensiones identitarias que atraviesan esta memoria. Fueron un instrumento importante en apoyo de los inmigrantes, elemento clave de la presencia española en América y de la visualización que desde América se tenía de esa presencia, y en alguna medida lo son en la actualidad cuando se encuentran inmersas en un proceso de notorio cambio por la evolución de las mismas en relación con los cambios en los países en que se asientan, la progresiva desaparición de una masa significativa de emigrantes nacidos en España -y el envejecimiento de los que quedan- y la revitalización de muchas y la creación de otras en relación con el proceso de modificación de la organización territorial en España.

\section{SIGNIFICACIÓN DEL ASOCIACIONISMO}

Uno de los aspectos que tal vez despiertan mayor interés en la temática migratoria actual se refiere a la incorporación de los inmigrantes a los países de recepción. Más aún, a los especialistas en este fenómeno les llama la atención la proliferación de asociaciones que los inmigrantes van fundando desde poco después de su llegada. Es significativa la práctica asociativa entre los emigrantes procedentes del sur de Europa, donde la experiencia asociativa era sensiblemente inferior a la existente en el norte (BARTHÉLEMY, 2003). Autores como Fernando Devoto consideran que la tendencia asociativa es mayor entre los emigrantes que entre los que permanecen en su país y refleja quizás la posible ruptura parcial del universo cultural y las redes de sociabilidad y subordinación en las que el emigrante estaba inserto en su lugar de origen (DEVOTO, 1992a: 174). Llama la atención también que para muchos de los inmigrantes españoles y de otras nacionalidades, las sociedades creadas en los países de destino constituyen la primera experiencia asociativa que tienen, en especial entre los procedentes del medio rural, que eran la mayoría. Una vez tenida la primera, sí es frecuente que la extiendan en los sucesivos destinos.

Se ha señalado que las asociaciones resultan fundamentales en la integración de los emigrantes, dado que tienen estrecha relación con la decisión, más o menos consciente, de asentarse en el nuevo destino, hacerse un espacio y construir, expresar y mantener una nueva identidad colectiva. Aunque el papel del asociacionismo en los procesos de integración sigue siendo controvertido. Una de las preocupaciones y retos de todo grupo inmigrante se 
centra en conseguir mantener y hacer compatibles su identidad primigenia con las señas de identidad de la sociedad en la que se inserta. Según se ha apuntado, en una primera etapa, cuando los inmigrantes se ubican en un escenario multiétnico, tratan de definir sus fronteras identitarias frente a la propia de la sociedad de acogida y otras presentes, incidiendo en sus rasgos culturales propios para reforzar su visibilidad. Cuando se ha conseguido esto, se pone el acento en la reinterpretación, redefinición e incluso la relativa invención de sus tradiciones propias, tratando paralelamente de integrarse en su nueva sociedad utilizando como palanca un amplio tejido asociativo étnico que les facilita influencia, en buena medida por la acción de sus líderes, y paralelamente les proporcionan servicios de educación, cultura, atención sanitaria y asistencial, además de ayuda mutua (SOLLORS, 1989; DEVoto, 1992b). A media que se van logrando estos objetivos y los inmigrantes comparten identidades cruzadas, mestizas o anfíbias por la relación entre la suya primigenia y la de la sociedad de acogida, los dirigentes procuran orientarlos progresivamente hacia un proceso de aculturación. A través de esta actuación como mediadores las elites de los colectivos inmigrantes alcanzan influencia y capital relacional entre las clases dirigentes del país receptor y al mismo tiempo reconocimiento en la sociedad de partida, liderazgo que se reduce al aceptar la segunda generación de inmigrantes los elementos culturales básicos y valores de la sociedad de acogida (HUGHES, MCGILL, 1952). Como apunta José Antonio Vidal, "este será, de alguna manera, el proceso de socialización de las colectividades españolas en América" (VIDAL 2008:304).

Los ámbitos de sociabilidad formales constituidos por los emigrantes cumplen al mismo tiempo, al menos en muchos casos, una doble función aparentemente contradictoria: recrean identidades primigenias de los inmigrantes y facilitan en cierta medida la integración en las sociedades a las que llegan como algo extraño. Sin duda se centran en el mantenimiento y recreación del sentido de lo propio mediante la incidencia y la recuperación de la historia, el mantenimiento de los símbolos, la valoración y defensa de la unidad del grupo frente a los "otros". Junto a prácticas centradas en el reforzamiento de los vínculos de solidaridad entre el grupo inmigrante, paralelamente las asociaciones sirven de plataformas de interlocución y presencia social y política en las sociedades de acogida y sus culturas. Desarrollan y favorecen estrategias de relación, negociación y asimilación con la sociedad de acogida. Aunque el tema del papel del asociacionismo en sentido general y del español en particular en los procesos de integración precisa un tratamiento más diversificado.

Además de la significación que las asociaciones cumplen en el proceso de 
integración, su importancia reside en la amplia gama de funciones que cumplen. Como ha señalado Consuelo Naranjo, "estas asociaciones actuaron de amortiguador del choque cultural a la llegada del individuo al posibilitar su incorporación-adaptación al nuevo país. Ellas proporcionaron al recién llegado la seguridad frente a un medio desconocido, le cubrían las necesidades afectivas, económicas y culturales en un primer momento" (NARANJO, 1988:96). Le ayudan a mantener su identidad étnica y le proporcionan puntos de referencia en cuanto a su identidad en el nuevo país, lo que posibilita que mantenga una continuidad con la vida que dejó atrás.

Estos espacios de sociabilidad responderán a la urgencia del encuentro, un encuentro repleto de imperativos afectivos, sociales e incluso económicos (COlEMAN, 1990). Económicos en algunos casos de especial indigencia, afectivos al permitir la reconstrucción de redes primarias desarticuladas por el alejamiento de su país de origen y reforzar espacios privados rotos por la emigración; y sociales, ya que surgen frente a la llamada a la reconstrucción de un pasado discontinuo generado por la propia emigración en el que interpretar comúnmente una historia compartida que preste la eficacia emotiva necesaria.

Las asociaciones son asimismo un centro de acceso a la información, aspecto fundamental para superar la incertidumbre que muchas veces acompaña al emigrante en un país desconocido, aunque las redes de relación hayan trabajado ya en esa dirección desde la etapa previa a la emigración. El asociacionismo, pues, va a ayudar a relativizar el paradigma del desarraigo derivado de la condición de migrante.

Entre las diversas funciones que realizan las asociaciones está una que facilita el propio inicio de la emigración. Muchas veces sirven de aval para sortear los trámites exigidos por distintos países para entrar en los mismos, lo que determina que en ocasiones los inmigrantes sean miembros de algunas de estas asociaciones antes de llegar al país donde han sido constituidas (NARANJO, 1987: 47-48).

Las asociaciones nos permiten conocer asimismo el imaginario de estos colectivos de emigrantes a partir de la iconografía y símbolos de las sociedades que crean y mediante las representaciones que reflejan en sus teatros, festivales y conmemoraciones patrióticas.

La proliferación de publicaciones periódicas creadas o alentadas por estas asociaciones aporta una información de gran interés sobre el quehacer sociocultural de los emigrantes en los lugares de acogida, como mecanismo de autoprotección y ayuda mutua. Esta prensa supone un elemento básico de de- 
fensa. Estas publicaciones -y otras internas de las asociaciones- constituyen una fuente de gran interés para reconstruir la historia de los inmigrantes, así como la reelaboración de sus culturas de origen en contacto con un nuevo contexto sociocultural (GUANCHE, 1999:256).

Por todo lo expuesto, Fernando Devoto ha resaltado que el asociacionismo de la emigración, al margen la desigual atención que ha tenido en los lugares de origen, constituye un capítulo mayor de la historia social de los países receptores del flujo migratorio (DEVOTO, 1992a:174). Sin embargo, a pesar de ello, al proceso asociacionista constituido por los emigrantes se ha prestado insuficiente atención.

\section{ASOCIACIONISMO ESPAÑOL EN AMÉRICA}

Ha habido insuficiente atención en general y menor en el caso español. Sin embargo, en conjunto, los españoles darán lugar en América, fundamentalmente hasta los años treinta del siglo XX, a un muy notable proceso asociacionista que a pesar de los estudios aparecidos en especial en torno a la efemérides del quinto centenario del descubrimiento y el interés por los estudios migratorios en algunas regiones, no ha recibido la atención historiográfica que merece, carencia que es extensible al conjunto de los estudios sobre sociabilidad en España (CANAL, 1992; ARIÑO, 2004).

Sin embargo, tuvo una extraordinaria importancia. Efectivamente, una de las características más notables del proceso de integración de los emigrantes españoles a las sociedades americanas durante los siglos XIX y XX ha sido la creación y desarrollo de un movimiento asociativo que los representaba. Estas asociaciones constituirán una plataforma de relación entre los propios inmigrantes, pero también con sus lugares de origen y con España.

Seguramente tenía razón el miembro de la Academia Gallega Adolfo Calveiro Couto cuando afirmaba en 1964 que "lo que representan a beneficio de sus afiliados o socios, las instituciones de naturaleza similar a Naturales de Ortigueira -ésta única en Cuba, por el número de los servicios que presta a sus miembros-, no pueden imaginárselo siquiera quienes no conozcan, directa e íntimamente, los móviles que las inspiraron y los modos y procedimientos para que las mismas se desarrollen, sostengan y rindan sus frutos naturales" (CALVEIRO, 1964).

El asociacionismo español entre la emigración en América muestra diversas facetas que deberían reflejar su importancia. Una, no necesariamente la más relevante, su dimensión numérica. Como ejemplo puede valer considerar que, en un momento determinado, un tercio de la colonia española en Cuba era miembro de alguna asociación. En los años cincuenta del siglo pasado, 
las sociedades españolas en la mayor de las Antillas tenían unos 400.000 afiliados, con entidades como el Centro Asturiano que casi llega a los 100.000, la Asociación Hijas de Galicia que supera esta cifra, el Centro de Dependientes del Comercio de La Habana que alcanza los 74.000, o el Centro Gallego, con 55.000 en 1957. En los años treinta la Asociación Española de Socorros Mutuos de Buenos Aires tenía 31.000 asociados y el Centro Gallego 27.000. Por esos mismos años la Asociación Española de Socorros Mutuos de Montevideo superaba los 18.000 socios y en los años setenta la Hermandad Gallega de Venezuela los 18.000. El Centro Asturiano de México tenía en 2004 14.000 y la Asociación Canaria de Cuba en torno a 30.000. Más significativa es sin duda su labor: Además de su actuación benéfica, asistencial y de ayuda mutua, fundamental en el plano sanitario como puede comprobarse en las memorias de muchas de estas asociaciones, llevan a cabo una muy significativa labor recreativa y cultural de mantenimiento y redefinición de identidades diversas: nacional, regionales y provinciales, en general no contradictorias, pero sí en algunos casos.

Habría que tener en cuenta la percepción de los propios emigrantes que consideran a estas asociaciones fundamentales en el proceso de adaptación a los lugares a los que llegan: "El Centro Asturiano -afirmaba en 2006 el Presidente de la Sociedad Asturiana de Beneficencia en Cuba-, como otras sociedades españolas, jugó un papel muy importante para que los emigrantes, que llegábamos de España, encontráramos trabajo, amigos y, lo que es muy importante, conociéramos las "reglas del juego" del país al que llegábamos, que, aunque pareciera menos, era un país extranjero"".

\section{IV. ¿A QUÉ RESPONDE EL ASOCIACIONISMO ESPAÑOL EN AMÉRICA?}

Como para el conjunto del asociacionismo, la motivación también es compleja entre las formas de asociacionismo voluntario constituidas por los inmigrantes españoles y tiene que ver en buena medida en un principio con la insuficiencia o la práctica inexistencia de servicios básicos del Estado como la atención sanitaria y educativa. Las asociaciones buscan la superación de problemas y también responden al intento de reinventar un sentido provisorio de la comunidad añorada -se persiguen enclaves para la convivencia, la reconstrucción de vínculos y la producción de identidades. Asociacionismo cultural y festivo, convivencial y recreativo, como se refleja en las asocia-

\footnotetext{
${ }^{1}$ Entrevista con Constantino Díaz Luces, "Constante", Presidente de la Sociedad de Beneficencia Asturiana y durante 32 años empleado en el Centro Asturiano. La Habana, abril de 2006.
} 
ciones que se asientan sobre la actividad recreativa que se centra en la distracción, la evasión y las practicas festivas. Es decir, hay asociaciones orientadas estrictamente a la sociabilidad y otras centradas en la solidaridad o la ayuda mutua y en ocasiones algunas responden también a las dificultades que tienen los inmigrantes para la participación política directa, aunque las asociaciones constituidas por la emigración económica inciden generalmente en su carácter formalmente apolítico. Sin olvidar las sociedades estrictamente sindicales o políticas. Motivación compleja y estructura asimétrica, por lo que hay que considerar el carácter multifactorial de la dinámica de la producción asociativa entre los inmigrantes, teniendo en cuenta que existen múltiples fuentes de la asociatividad (tanto convivencial como productora de servicios y altruista). Diversidad, complejidad y variada vitalidad de este asociacionismo español que se inicia en torno a mediados del XIX y sigue en la actualidad.

Como ha apuntado Moisés Llordén, las primeras asociaciones de los inmigrantes españoles en América en la época contemporánea responden al intento de hacer frente a algunos de los problemas que se le plantean en los países de acogida, que al margen de las concomitancias culturales, étnicas o de otro tipo, son conscientes de un cierto grado de inseguridad en un medio distinto a aquel del que proceden (LLORDÉN, 1992). Responden sin duda a la necesidade dotarse de una serie de servicios y ayudas cuya urgencia siente con fuerza la emigración española, como ocurre con otros colectivos de emigrantes. Tienen también sin duda un componente de solidaridad y de altruismo en muchos casos. Y a esas finalidades más perentorias se van uniendo otras de motivación diversa, desde las políticas a las deportivas, conformando un abigarrado mosaico de espacios formales de sociabilidad que inciden en aspectos fundamentales para el emigrante como la integración y la identidad.

En la conformación de estas asociaciones juega muchas veces un papel relevante la identidad étnica nacional, pero en ocasiones constituían una forma de institucionalizar la importancia de los lazos regionales, que con frecuencia se superponen a los de vecindad y familia, y al mismo tiempo ofrecen determinadas funciones propias de la unidad familiar, tratando de llenar la nostalgia que siente el inmigrante. Jesús Guanche considera que fue "en América donde la concurrencia de elementos étnicos hispánicos (...) contribuyó decisivamente a la reafirmación de una autoconciencia étnica hispánica en oposición al arraigado regionalismo peninsular"'(GUANCHE, 1983:127), afirmación que hay que matizar según para qué periodos de la emigración y según países, pues en el caso del asociacionismo español las instituciones regionales tienen en algunos países de acogida una vitalidad similar o mayor 
que las globalmente españolas. Como afirma Kenny refiriéndose a México, el asociacionismo español de base regional supone para el emigrante una "base para hacer alianzas en un nivel menos abstracto y más con- fiable que la nación, pero no tan seguro como la familia o el pueblo" (KENNY, 1979:84). Hay que tener en cuenta que no siempre se daba ni mucho menos una contradicción de fondo entre diversas formas de identidad, lo que se traducía en la pertenencia de los mismos individuos a asociaciones distintas, fundamentalmente los grupos dirigentes ${ }^{2}$. En la colonia española en América van a convivir asociaciones globalmente españolas con otras de agrupamiento regional, provincial, comarcal e incluso local. Pero, por otro lado, en algunos casos, como ocurre en Buenos Aires, no pocos inmigrantes estarán integrados en sociedades de socorros mutuos formadas por distintas nacionalidades, lo que cuestiona en cierta medida la voluntad étnica de los mismos (SÁNCHEZ ALONSO, 1992: 34-35).

\section{TIPOLOGÍA DE LAS ASOCIACIONES DE LOS INMIGRAN- TES ESPAÑOLES}

No es fácil establecer una adecuada tipología de asociaciones españolas en América, teniendo en cuenta la mencionada diversidad de motivaciones a que responden. Las perspectivas para el emigrante que llegaba a América durante el siglo XIX sin el apoyo de familiares o coterráneos en el país de acogida no eran halagüeñas y en muchos casos sus esperanzas de mejora se frustraban rápidamente. Esta situación era de sobra conocida, y temida, por los emigrantes con buena situación económica, lo que explica que las primeras asociaciones que se forman sean de beneficencia, que responden a factores de carácter humanitario, de vinculación afectiva con los paisanos y continúan una tradición ya existente en el Antiguo Régimen. Como respuesta a esa difícil situación económica del recién llegado surgen también, y ahora desde las filas de los emigrantes más desfavorecidos, las sociedades de socorros mutuos. A éstas seguirán pronto otras donde a esa finalidad asistencial se unen otras de carácter recreativo, cultural, social, educativo, etc.

Responde la experiencia asociativa, por tanto, a una motivación múltiple y de ahí lo múltiple de sus formas. El fomento de las relaciones personales y profesionales entre personas del mismo grupo nacional, e incluso regional, provincial y de lugar concreto de origen; intereses mutualistas, sindicales, labores de beneficencia, asistenciales, recreativas, culturales, educativas, políticas, económicas, entre otras, están en el origen de las iniciativas asocia-

\footnotetext{
${ }^{2}$ La Administración española sí verá con preocupación la creación de asociaciones que refuerzan la identidad regional. AMAE. H. 2351. Cuba, Política Exterior, leg. 1911.
} 
cionistas. Aspiraciones étnicas, carencias afectivas y necesidad de ciertos servicios.

Muchas veces las asociaciones surgidas con una finalidad concreta van incorporando otros de los servicios mencionados en función de los intereses de los asociados. Las sociedades de beneficencia implantan en ocasiones fines mutuales, y las de socorros mutuos servicios de beneficencia, mientras los centros regionales suelen presentar una gama amplia de objetivos. En ocasiones surgen distintas asociaciones como repuesta a un mismo problema, pero desde segmentos sociales y con objetivos y planteamientos ideológicos distintos. De lo expuesto se deriva la dificultad para establecer una clasificación de estas asociaciones que, siendo operativa, responda a una valoración general del papel de las mismas.

\section{EL ASOCIACIONISMO EN LOS PAÍSES AMERICANOS DE MAYOR INMIGRACIÓN ESPAÑOLA}

Siendo los dos países que acogen los mayores contingentes de la emigración española, será en Cuba y Argentina donde tenga un mayor desarrollo el asociacionismo (BLANCO y FERNANDEZ, 2005). El mantenimiento de la vinculación colonial durante el siglo XIX y el enorme peso que mantuvo la emigración española en la Mayor de las Antillas fueron factores muy relevantes en el modelado del movimiento asociativo en Cuba, diferenciándolo en algunos aspectos de lo ocurrido en los países del continente. La principal de esas diferencias se halla en el surgimiento, desde épocas bastante tempranas, de entidades que se fueron conformando en base a criterios de agrupamiento regional, en lugar de agrupar a los inmigrantes de toda España. Así, ya en 1841 se fundó la Sociedad de Beneficencia de Naturales de Cataluña, presidida por el capitán general de la Isla. Mientras en los países en donde el enfrentamiento con los residentes españoles había sido agudo durante las guerras de independencia (como México o Venezuela) o en aquellos que incorporaron un porcentaje elevado de inmigrantes de otros orígenes (casos de Brasil, Argentina, Uruguay y Chile), la formación de sociedades de ayuda mutua que se definían como españolas, sin otra distinción, fue el procedimiento más habitual para apelar a la identidad étnica hasta comienzos del siglo XX, en la isla caribeña dominó claramente el modelo asociativo regionalista.

Cuando las tendencias independentistas se hicieron visibles en las últimas colonias se fundaron los casinos españoles, inicialmente en La Habana (1869) y luego en otras ciudades de la isla. Uno de sus objetivos consistía justamente en reducir las tensiones entre los residentes españoles y la población cubana, aunque luego de la independencia se concentraron más bien en 
las funciones recreativas y culturales. En cualquier caso, la variante regionalista siguió siendo dominante, extendiéndose por las distintas comunidades que contaban con una importante presencia en la isla, como los gallegos, asturianos, canarios, castellanos, vascos o andaluces. Las sociedades regionales de beneficencia contribuyeron a mitigar el impacto de las crisis más agudas que se abatieron sobre la economía cubana, como la de comienzos de la década de 1920 y la derivada del crack del 29, momentos en que fue necesario financiar los pasajes de repatriación de paisanos indigentes. Por su parte, el Centro Gallego (1879), el Centro Asturiano (1886), la Asociación Canaria (1906) o el Centro Castellano(1909) contaron con miles de afiliados y desarrollaron una oferta educativa y un sistema médico-farmacéutico de notable complejidad que se sustentaba en el pago de cuotas y en inversiones de capital. A diferencia de las sociedades de beneficencia, estos centros proclamaban la igualdad de sus miembros y no reconocían socios protectores con mayor poder de decisión, si bien los afiliados de posición económica más relevante hacían frecuentemente aportaciones sustanciosas. Ambas vertientes del asistencialismo -la benéfica y la propiamente mutualista- estuvieron presentes en la mayoría de los países latinoamericanos de fuerte inmigración española, aunque fue en Cuba y Argentina donde alcanzaron su mayor grado de desarrollo.

Por otro lado, La Habana constituyó, junto con Buenos Aires y en menor medida Montevideo, Sao Paulo, Río de Janeiro y Nueva York, uno de los escenarios en donde llegó a desenvolverse un movimiento asociativo muy peculiar, protagonizado fundamentalmente por la emigración gallega, pero también presente entre asturianos y castellanos. Nos referimos a las entidades de base local o comarcal, que mantuvieron un intenso y prolongado contacto con las aldeas de origen de los emigrantes. Los objetivos de estas asociaciones, que agrupaban a los originarios de una determinada parroquia, ayuntamiento, comarca o partido judicial, eran variados: la promoción de la educación primaria en la tierra de origen, el fomento de las obras de infraestructura o de salud pública, la difusión de técnicas agrícolas a veces aprendidas en los países de destino, etc. En algunas ocasiones, el perfil más bien apolítico de sus actividades fue desplazado por unos móviles claramente "regeneracionistas", como la lucha contra el caciquismo dominante en la España de la Restauración o la defensa de un cierto ideario republicano o socialista. En cualquier caso, las iniciativas en favor de la redención material, educativa y moral de los labriegos gallegos o asturianos formaban parte de una compleja interacción entre las aldeas de origen y las ciudades americanas, cuyo protagonista principal fue una elite emigrante o exiliada por razones políticas en el último cuarto del siglo XIX (NUÑEZ SEIXAS, 1998). 
La relación entre el asistencialismo basado en la beneficencia y el que defendió los principios de la ayuda mutua no fue en todas partes de competencia o confrontación. De hecho, en algunos países existió complementariedad entre las dos vertientes y en otros el predominio de una de ellas se ocultaba debajo del empleo de la denominación de la otra. Así ocurrió en Puerto Rico, donde la Sociedad de Auxilio Mutuo de la capital (1883) nació como una especie de rama social del Casino Español. Pese a su nombre, se trataba en realidad de una entidad benéfica conducida rígidamente por los dirigentes del Casino, fervientes católicos y militantes del Partido Incondicional que defendía el statu quo previo a la guerra con Estados Unidos (GARCíA RODRÍGUEZ, 1983:61-62). Precisamente la guerra llevó en 1899 a un intento de fusión con el Casino que no prosperó, pero que dejó en evidencia los estrechos vínculos al interior de la elite que dirigía la Sociedad y que ofrecía sus servicios asistenciales a una corriente inmigratoria de todos modos muy escasa desde comienzos de siglo XX. La exigüidad del flujo inmigratorio se dio en otros lugares del Caribe, haciendo que a veces el desarrollo del mutualismo español se enfrentara a dificultades insalvables. Es lo que ocurre en la República Dominicana, donde el mutualismo debió ser reemplazado por una red de centros patriótico-culturales, como la Casa de España, fundada en 1917 en Santo Domingo. Estas entidades primaron el sostenimiento de la unidad étnica y cultural frente al avance de la influencia norteamericana, o bien la defensa de determinados intereses específicos como los de los pequeños comerciantes españoles dispersos por el país.

El cuarto de millón de españoles que emigraron a Estados Unidos, en particular en las dos primeras décadas del XX, siguió la larga tradición asociativa de los estadounidenses y constituyeron un gran número de asociaciones, en especial en el estado de Nueva York, zona preferida de asentamiento y ciudad a la que llegan la mayoría de ellos. En esta ciudad existían asociaciones globalmente españolas y otras que agrupaban a gallegos, asturianos, vascos, aragoneses, andaluces y valencianos que, al restringirse la inmigración, desde finales de los años 30 tienden a integrarse en asociaciones nacionales, con excepción de los vascos, lo que ocurre en el conjunto del país, además de constituir sociedades globalmente "hispanas" (RUEDA, 2008: 38). A destacar asimismo el asociacionismo conformado en Florida, alimentado por los españoles que han llegado desde Cuba.

La escasa entidad del flujo inmigratorio español fue un problema que estuvo presente en México, donde el asociacionismo étnico sólo logró un asentamiento estable en las grandes ciudades, aunque fue capaz de anticiparse al catolicismo social -con el que compartía muchos de sus presupuestos- y al mutualismo de resistencia (MELGAR BAO 1988:112-113). La Sociedad Es- 
pañola de Beneficencia, surgida en Tampico en 1840 como entidad de ayuda a los españoles necesitados, incorporó después a sus funciones la de asistencia sanitaria y construyó un hospital para la colectividad. Su homónima de Puebla (1860) sufrió diversas vicisitudes, como una serie de mortíferas epidemias que mermaron drásticamente su masa de afiliados, pero también fue capaz de erigir en 1890 un centro de salud de respetables dimensiones si se lo compara con su reducido padrón social. La matriz benéfico-asistencial, también central en la de Tampico, era acompañada en este caso por una fuerte influencia de la iglesia local en la vida de la sociedad.

Desde comienzos del siglo XX las asociaciones españolas de ayuda mutua se extendieron a otras ciudades del territorio mexicano, pero su capacidad para implantar y sostener un moderno sistema de salud seguía siendo muy limitada, teniendo en cuenta que la mayor parte de aquéllas no superaba el centenar de integrantes ${ }^{3}$. Distinta fue la situación de las instituciones que apuntaron desde sus orígenes al reclutamiento de un sector reducido pero próspero de la colectividad, como el Centro Asturiano, el Gallego, el Vasco o el Casino Español (ORDOÑEZ, 2008). Su trayectoria ascendente en cuanto a número de afiliados, patrimonios acumulados o influencia en la sociedad mexicana contrasta también con las permanentes dificultades financieras a las que se vieron sometidos los centros creados por la emigración política derivada de la guerra civil española.

Por su parte, la reducida colectividad española de Guatemala contó con su propia asociación benéfica desde 1866. En ella se combinaban las motivaciones caritativas y paternalistas con un evidente propósito de consolidación de la relevancia social de su grupo dirigente, proveniente de las más altas posiciones económicas y políticas de Guatemala. Desde 1880 extendió su acción hacia el interior, pese a la permanente inestabilidad política y al cuadro de pobreza generalizada. En 1897, con ocasión de la Guerra de Cuba, reformó sus estatutos, incorporando el propósito de reforzar la unidad de los españoles y participó activamente en la colaboración pecuniaria con la marina de guerra española. En 1910 permitió el ingreso de mujeres como afiliadas y en 1925 organizó su propia sección de auxilios mutuos, lo que fue posible debido al gran aumento de su padrón social en esos años. Sin embargo, su gobierno y administración siguieron en manos de un reducido grupo de comerciantes y profesionales, poco diferente del que la había fundado sesenta años antes (PRESA FERNÁNDEZ, 1987).

\footnotetext{
${ }^{3}$ Circular dactilografiada de la Unión Española, 8 de agosto de 1916, conservada en Archivo General de la Administración, Alcalá de Henares, Embajada Española en México, Caja 319.
} 
Venezuela fue un destino tardío para la inmigración de origen español, que no reviste importancia, más allá de la recepción de pequeños grupos de exiliados tras la guerra civil española, hasta los años cincuenta del XX con la profunda transformación económica que supuso el auge petrolífero y la política inmigratoria de "puertas abiertas" que aplicó el gobierno del dictador Marcos Pérez Jiménez. Este fuerte contingente inmigratorio español se asentó fundamentalmente en Caracas, destacando los amplios grupos de canarios y gallegos. Por ello descollará el asociacionismo conformado por estos colectivos regionales, con asociaciones como la Hermandad Gallega de Venezuela (1960) que aglutina a otras asociaciones previamente existentes y en la que se integran otros colectivos regionales españoles, o el Hogar Canario (1942) y finalmente la Asociación Canaria de Venezuela (1966), que pretende vertebrar la amplia comunidad canaria (HERNANDEZ GONZÁLEZ, 2008:104-105), además de un pujante asociacionismo de marcado carácter político como el Centro Vasco (1941).

Si nos centramos en los países sudamericanos que acogieron los mayores contingentes de población europea, llama la atención la exuberancia del movimiento asociativo. En el Río de la Plata, las sociedades de ayuda mutua que se definían como españolas buscaron agrupar sin distinciones regionales a los inmigrantes procedentes de España. Además, se extendieron ampliamente por el territorio de los países receptores, desde las grandes ciudades del litoral hasta localidades alejadas y poco pobladas. Aun en la actualidad son visibles los edificios de las AESM en muchos de esos pueblos y resalta el lugar que siguen ocupando como centros de reunión o de festividades, si bien las funciones de estas sociedades son mucho más limitadas que en el pasado o han debido adecuarse al cambio de los tiempos, incorporando actividades dirigidas a la población en general y no sólo a los descendientes de españoles. En Argentina, la importancia de estas asociaciones no podría equipararse con la de las italianas si sólo tuviéramos en cuenta la cantidad de entidades o el número total de socios. Sin embargo, superaron claramente a estas últimas en cuanto al promedio de afiliados por sociedad. El discurso pan-hispánico de sus elites dirigentes, generalmente orientado al apoliticismo y centrado en la calidad de los servicios mutualistas, marcó una importante diferencia con el caso de los italianos, en el que las disputas entre monárquicos y republicanos, y luego entre pro-fascistas y anti-fascistas, llevaron a frecuentes fracturas y escisiones (DEVOTO, 2003:310-319).

La principal de estas instituciones, que sobrevivió en Buenos Aires hasta 1987, llegó a contar con más de veinte mil miembros en la década del veinte del siglo pasado, cifra que superaba a la de cualquier otra asociación voluntaria existente por entonces, fuese argentina, extranjera o cosmopolita. La 
variedad de sus servicios médico-farmacéuticos y la extensa red de reciprocidades que la vinculaban con otras entidades del mismo tipo en las provincias del interior argentino y en los países limítrofes hicieron incluso que se la mencionara como un ejemplo en el debate sobre la creación del seguro social durante la Segunda República española. Pese a ello, la enorme presencia de los españoles en la capital de la Argentina -más de trescientos mil según el censo de 1914, sin contar a sus descendientes- hizo que aquélla fuera capaz de albergar también al Centro Gallego (1907), una entidad asimismo orientada al mutualismo que llegó a superar la cantidad de afiliados de la AESM después de 1930. En cambio, otras asociaciones de matriz regional, como el Centre Català o el Laurak Bat, surgidos en la década de 1880, se concentraron más decididamente en la sociabilidad entre paisanos y en la defensa de la identidad cultural. En el caso del primero, una escisión producida en 1908 dio lugar a un catalanismo de perfil más político, con la fundación del Casal Català (FERNÁNDEZ, 2008). Por otro lado, el prestigio de algunos dirigentes de la colectividad española que destacaban en el asociacionismo y la prensa étnicos y la encumbrada posición en la sociedad porteña alcanzada por un grupo de exiliados que llegaron tras el Sexenio Democrático constituyeron importantes incentivos para la formación y desarrollo de la Liga Republicana Española a comienzos del siglo XX (DUARTE, 1998). Este movimiento no se definió en un sentido hostil u opositor respecto de otras manifestaciones políticas previas de los españoles asentados en la Argentina, como la Asociación Patriótica, que había sido creada en medio del fervor hispanista del período de la guerra de Cuba y que después de la misma habría de consagrarse a otros objetivos como la defensa del prestigio cultural y científico de España en una sociedad en la que dichos valores seguían estando poco acreditados (FERNÁNDEZ, 1987).

Dentro del territorio brasileño el asociacionismo español alcanzó su principal desarrollo en el Estado de Sao Paulo, donde vivía alrededor del ochenta por ciento del total de inmigrantes de ese origen radicados en el país (CANOVAS, 2008). El modelo netamente dominante aquí fue el de las sociedades de socorros mutuos que abarcaban a todos los españoles sin distinción (GONZALEZ MARTINEZ, 2008). Dadas las apremiantes necesidades de financiación del asistencialismo y las dificultades de muchos de los inmigrantes (pertenecientes en una vasta proporción a los estratos de trabajadores urbanos y rurales) para abonar regularmente sus cuotas, estas sociedades debieron abrirse con bastante rapidez a los descendientes de aquéllos ya nacidos en Brasil e incluso establecer convenios de atención de los afiliados con las entidades más poderosas que habían creado los italianos (GONZÁLEZ MARTÍNEZ, 1990:208-210). El mutualismo español se fue extendiendo desde la capital del Estado, donde se fundó la primera entidad en 1898, hacia San- 
tos y toda el área cafetalera. Como expresaban de manera idéntica los estatutos de algunas de esas mutuales, lo que se perseguía era "fomentar el espíritu de asociación que debe unir a los hombres en los sagrados vínculos de fraternidad y proporcionarles medios de instrucción, socorro y auxilio mutuo" ${ }^{4}$.

En otras regiones del Brasil el asociacionismo mutualista, combinado a veces con el de la beneficencia, había comenzado a desarrollarse con anterioridad a la expansión cafetalera que atrajo a la mayoría de los españoles hacia Sao Paulo. En Río de Janeiro, por ejemplo, ya existía una sociedad de ese tipo desde 1859, mientras que otras similares fueron fundadas en Bagé (1868), Salvador de Bahía (1885) y Porto Alegre (1893). Todas ellas mantenían una clara orientación hacia los servicios médicos y farmacéuticos, por lo que debieron soportar fuertes crisis durante las diversas epidemias de la segunda mitad del siglo XIX (BLANCO, 2009). Desde la perspectiva socioocupacional, sus padrones estaban mayoritariamente integrados por pequeños comerciantes, empleados, dependientes y en menor medida artesanos, es decir, por estratos urbanos a los que el mutualismo ofrecía una cobertura asistencial relativamente eficiente y asequible. En cuanto a los orígenes regionales, los gallegos constituyeron el grupo más abundante en los padrones de las asociaciones españolas, a la vez que fundaron sus propios Centros en Río, Sao Paulo y Belem do Pará (FERNÁNDEZ, 1992:343-344).

En Uruguay la inmigración española fue menos numerosa que en Brasil en cantidades absolutas, pero su importancia relativa fue claramente mayor (ZUBILlaGA, 2008). El asociacionismo de ese origen nació al mismo tiempo que el de la Argentina, con la Sociedad de Socorros Mutuos de Montevideo fundada en 1853. Tres décadas más tarde logró instalar su hospital y para 1928 el número de afiliados había llegado a la enorme cifra de 18.000. Pese a que sus estatutos preveían también actividades culturales, su interés se concentró casi exclusivamente en los servicios de salud. Los grupos sociales en ella dominantes (pequeños comerciantes, artesanos, empleados, trabajadores calificados) fueron en general los que prevalecieron en las entidades del mismo tipo que se fueron creando en varias ciudades del interior en las décadas de 1860 y 1870. Entre ellos, los gallegos, aun no siendo tan dominantes como en el asociacionismo del Brasil, constituían el primer grupo regional, seguidos por asturianos, vascos y catalanes, y más de lejos por navarros, castellanos y andaluces. La defensa de los valores culturales de la tierra de origen frente al menosprecio que por ellos manifestaban algunos miembros de la clase dirigente uruguaya y el refuerzo de los vínculos con aquélla

${ }^{4}$ Centro Español de Cafelandia, Reglamento, Cafelandia, Tip.da Comarca de Pirajuhy, 1927; Centro Español de Catanduva, Reglamento General, Catanduva, s/d., 1926. 
fueron los objetivos que llevaron a la creación del Centro Gallego en 1879. La entidad trató de otorgar ciertos apoyos a los inmigrantes recién llegados, pero su interés se concentró sobre todo en la vertiente recreativo-cultural. Por ello quedó abierto un flanco para la creación de una entidad como la Casa de Galicia (1917), que asumió las funciones asistenciales a través de su sección de fomento y protección del trabajo (CAGIAO VILA, 1989:155-156).

Montevideo contó también, al igual que Buenos Aires, con una serie de instituciones étnicas que expresaron el ascenso social de sus elites, como la Cámara Española de Comercio (1888), que trataba de fomentar el intercambio económico y la navegación entre los dos países, el Club Español (1878), centro de sociabilidad de sólidas vinculaciones con la representación diplomática y el conservadurismo político, la Institución Cultural Española (1919), que promovió el contacto de las universidades rioplatenses con algunas de las figuras más prestigiosas de las ciencias y la cultura de España, o el Hospital-Sanatorio Español, inaugurado en 1909 con el propósito de ofrecer asistencia médica a los inmigrantes indigentes mediante las contribuciones de quienes podían pagar por su utilización, pero que con los años derivaría hacia la atención casi exclusiva de estos últimos (ZUBILLAGA, 2000).

Entre los países andinos, solamente Chile contaba a comienzos del siglo $\mathrm{XX}$ con una red significativa de sociedades que agrupaban a los residentes de origen español. En 1854 había sido creada la Sociedad Española de Beneficencia de Santiago y en ella se inspiró el surgimiento de otras entidades radicadas en Valparaíso, Iquique, Talca y Concepción durante las siguientes décadas. A fines de la de 1880 el crecimiento de la inmigración española permitió echar las bases del mutualismo, con la aparición de la primera sociedad de ese tipo, también en la capital. Por su parte, los grupos más relevantes de la colectividad constituyeron por entonces el Círculo Español, que apenas fundado sufrió la escisión de un núcleo pro-carlista con motivo de la muerte de Alfonso XII. El Círculo procuraba asumir la representación de todos los españoles frente a la dirigencia chilena en ocasiones como la del IV Centenario del Descubrimiento de América, pero ese intento era contestado por quienes alegaban que su composición era excesivamente elitista (PRESA, 1972). También lo sería desde principios de siglo por los defensores de un regionalismo de perfil político, sobre todo por la dirigencia del Centre Català (1906), que a través de la revista Germanor llevó adelante una intensa labor de activismo cultural e ideológico (MANENT, 1992:II,291 y JENSEN, 2008: 143-144).

\section{CONCLUSIÓN}

Una de las características más notables del proceso de integración de los 
emigrantes españoles en las sociedades americanas durante los siglos XIX y $\mathrm{XX}$ ha sido la creación y desarrollo de un movimiento asociativo que los representaba. Como afirma Alejandro Fernández, "las asociaciones creadas por los españoles en América constituyen una de sus huellas más persistentes, aun después que perdiera toda relevancia la corriente migratoria que le dio origen. Un esfuerzo de siglo y medio, concretado en cientos de asociaciones por el que desfilaron más de un millón de asociados tiene mucho que enseñar sobre las colectividades de emigrantes y sus relaciones con los países de acogida" (FERNÁNDEZ, 1992:331)

Dicho movimiento abarcó en realidad a más de dos mil entidades, muchas de las cuales aún subsisten, si bien en la mayor parte de los casos con una actividad que es sólo un pálido reflejo de la que mantenían hace cincuenta años o más. Dado que el grueso de los padrones estuvo conformado durante años por varones adultos, ese millón de afiliados supone más de una cuarta parte de los españoles que permanecieron en ultramar.

Será a partir de la segunda mitad del siglo XIX cuando el asociacionismo español adquiera relevancia y al mismo tiempo la complejidad a la que hemos hecho referencia, y su etapa de mayor significación coincidirá con el periodo de más flujo migratorio desde la segunda década del siglo XX hasta los años treinta. A partir de la década de 1960 este fenómeno asociacionista entra en paulatina decadencia por la reducción de la emigración, el debilitamiento de los lazos de estos emigrantes con sus lugares de origen y la absorción progresiva del Estado de algunas funciones como la atención sanitaria que habían jugado un papel clave en el desarrollo de no pocas de estas asociaciones.

\section{BIBLIOGRAFÍA}

ARIÑO, A. (2004):«Asociacionismo, ciudadanía y bienestar social», Papers, $\mathrm{n}^{\circ} 74$, 85-110.

BARTHÉLEMY, M. (2003): Asociaciones: ¿una nueva era de la participación?, Valencia, Tirant lo Blanch.

Blanco, J. A. (ed.) (2008): El asociacionismo en la emigración española a Améri$c a$, Salamanca, Junta de Castilla y León/UNED Zamora

BLANCO, J. A. (2009): «Emigración y asociacionismo español en Brasil», en SousA, Fernando, MARTINS, Isménia y MATOS Izilda (coords.), Nas duas margens. Os portugueses no Brasil, Oporto, CEPESE.

CAgiaO, P. (1989): «Inserción laboral de la inmigración gallega en Montevideo, (1900-1930)», Revista da Comisión Galega do Quinto Centenario, no 4.

CAlveiro, A. (1964): «Breves consideraciones inspiradas en la creación de Naturales de Ortigueira», en Memorias de Naturales de Ortigueira, La Habana, Imp. Mario Pedrol Piñeiro/Naturales de Ortigueira. 
CANal, J. (1992): «La sociabilidad en los estudios sobre la España Contemporánea», Historia Contemporánea, $\mathrm{n}^{\circ}$ 7, 183-205.

CANOVAS, M. (2008):«El Diario Español y las asociaciones españolas en Sao Paulo en las primeras décadas del siglo XX», en BlanCO, J. A. (ed.), El asociacionismo en la emigración española a América, Salamanca, Junta de Castilla y León/UNED Zamora, 389-422.

Coleman, J. (1990): Fundations of Social Theory, Harvard, Harvard University Press.

Devoto, F. (1992a): «La experiencia mutualista italiana en la Argentina: un debate», en Devoto, F. y Míguez, E. (comps.), Asociacionismo, trabajo e identidad étni$\mathrm{ca}$, Buenos Aires, CEMLA-CSER-IEHS.

Devoto, F. (1992b): «¿Inventando a los italianos? Imágenes de los primeros inmigrantes en Buenos Aires (1810-1880)», Anuario del IEHS, VII, 121-135.

DUARTE, Á. (1998): La república del emigrante. La cultura de los españoles en Argentina (1875-1910), Lleida, Milenio

FERNÁNDEZ, A. (1987): «Patria y cultura. Aspectos de la acción de la élite española de Buenos Aires (1880-1920)», Estudios Migratorios Latinoamericanos, A. 2, no 6-7, 291-307.

FERNÁNDEZ, A. (1992):«Mutualismo y asociacionismo», en VIVES, Pedro, VEGA, Pepa y OYAMBURU, Jesús (comps.), Historia general de la emigración española a Iberoamérica, Madrid, CEDEAL/Historia 16, 331-357.

FERNÁNDEZ, A. (2008): «El asociacionismo español en Argentina: una perspectiva de largo plazo», en BLANCO, J. A. (ed.), El asociacionismo en la emigración española a América, Salamanca, Junta de Castilla y León/UNED Zamora, 469501.

García Rodríguez, J. M. (1983): Sociedad Española de Auxilio Mutuo: los años fundacionales, San Juan de Puerto Rico.

GonZALEZ MARTíneZ, E. (1990): Café e inmigración: los españoles en Sao Paulo, 1880-1930, Madrid, CEDEAL.

GuAnche, J. (1983): Procesos etnoculturales de Cuba, La Habana, Editorial Letras Cubanas.

GuANCHE, J. (1999): España en la savia de Cuba, La Habana, Editorial de Ciencias Sociales.

Hughes, E., Mcgill, H. (1952): Where People Meet: Racial and Etnic Frontiers, Glencoe, Free Press.

JENSEN, S. (2008): «Asociacionismo catalán en América Latina. Notas al estudio de un terreno poco explorado», Blanco, J. A. (ed.), El asociacionismo en la emigración española a América, Salamanca, Junta de Castilla y León/UNED Zamora.

KenNy, M. et AL. (1979): Inmigrantes y refugiados españoles en México, siglo XX, México. D.F., Ediciones de la Casa Chata.

LLORDÉN, M. (1992): «Las asociaciones españolas de emigrantes», en MORALES, M. del C. y Llordén, M., Arte, Cultura y Sociedad en la emigración española a América, Oviedo, Universidad de Oviedo, 9-55.

MElgAR BAO, R. (1988): El movimiento obrero latinoamericano, Madrid, Alianza. 
NARANJO, C. (1987): Cuba vista por el emigrante español, 1900-1959. Un ensayo de historia oral, Madrid, CSIC.

NARANJO, C. (1988): Del campo a la bodega: recuerdos de gallegos en Cuba (siglo $X X)$, Sada (A Coruña), Ediciós do Castro.

NuÑEZ SEIXAS, X. M.: Emigrantes, caciques e indianos. O influxo sociopolítico da emigración transoceánica en Galicia (1900-1930), Vigo, Eds. Xerais.

ORDÓÑEZ, N. V. (2008): «Asociaciones e ideología en la colonia española de México», en Blanco, J. A. (ed.), El asociacionismo en la emigración española a América, Salamanca, Junta de Castilla y León/UNED Zamora, 277-302.

PRESA, J. (1987): La Sociedad Española de Beneficencia de Guatemala, Guatemala, Editora Nacional.

SAnCHEZ AlOnso, B. (1992): La inmigración española en Argentina. Siglos XIX y $X X$. Columbres, Archivo de Indianos.

Sollors, W. (ed.) (1989): The Invention of Ethnicity, Nueva York, Oxford University Press.

VIDAL, J. A. (2008): «El asociacionismo gallego en Cuba», en BLANCO, Juan Andrés (ed.), El asociacionismo en la emigración española a América, Salamanca, Junta de Castilla y León/UNED Zamora.

ZubiLlaGA, C. (2000): «Notas para una tipología de los liderazgos en la inmigración española en Uruguay, 1870-1960», en Estudios Migratorios Latino Americanos, $\mathrm{n}^{\circ} 44,147-163$.

ZubILlaGA, C. (2008): «Asociacionismo español de inmigración en Uruguay», en BlanCO, J. A. (ed.). El asociacionismo en la emigración española a América, Salamanca: Junta de Castilla y León/UNED Zamora, 423-467. 